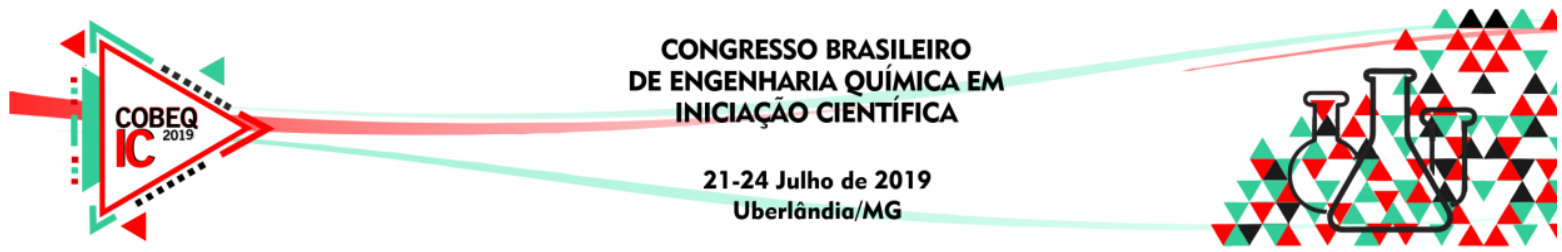

\title{
GERAÇÃO DE ENERGIA À PARTIR DE RESÍDUOS INDUSTRIAIS DO CARVÃO VEGETAL E BIODIESEL
}

\author{
P. R. F. FONSECA ${ }^{1}$, S. M. DE ALMEIDA ${ }^{2}$, M. P. OLIVERIA ${ }^{3}$ e A. F. D. JÚNIOR ${ }^{3}$ \\ ${ }^{1}$ Universidade Federal do Espírito Santo - Campus de Alegre, Programa de Pós-Graduação \\ em Engenharia Química (PPEQ/UFES). \\ ${ }^{2}$ Universidade Federal do Espírito Santo - Campus de Alegre, Curso de Engenharia Química \\ (DEQ/UFES). \\ ${ }^{3}$ Universidade Federal do Espírito Santo - Campus de Alegre, Departamento de Ciências \\ Florestais e da Madeireira. \\ E-mail para contato: pauloricardofonseca1@ gmail.com
}

\begin{abstract}
RESUMO - Este trabalho teve como objetivo avaliar a viabilidade técnica da produção de briquetes a partir de finos de carvão vegetal e de glicerina bruta, para a geração de energia. Foram produzidos briquetes de três composições de glicerina, de aglutinante e duas pressões de compactação, por meio da prensa hidráulica. A qualidade dos briquetes foi avaliada por meio de análises de resistência ao impacto, teor de cinzas e poder calorífico. Em relação à resistência ao impacto, em diferentes composições, os briquetes produzidos foram capazes de suportar 3 quedas. Em termos de teor de cinzas, os briquetes com composição de $65 \%$ de carvão, $20 \%$ de glicerina e $15 \%$ de aglutinante apresentaram os melhores resultados. Já no poder calorífico, os melhores resultados foram obtidos na composição de $70 \%$ de carvão, $20 \%$ de glicerina e $10 \%$ de aglutinante. Sendo o último, considerado o melhor briquete, pois além de apresentar valores semelhantes de teor de cinzas, possui melhor poder calorífico e utiliza maior quantidade de finos de carvão.
\end{abstract}

\section{INTRODUÇÃO}

Normalmente na produção industrial de bens de consumo são gerados resíduos que necessitam de uma destinação adequada proporcionam a buscar novas alternativas para aproveitar os materiais. Uma opção para os resíduos com potencial energético é a briquetagem, uma técnica na qual a biomassa é prensada em blocos denominados briquetes, nos quais tornam as matérias-primas de baixo custo para a geração de energia térmica. Geralmente os briquetes apresentam formato cilíndrico, 5 vezes mais energia que o metro cúbico do resíduo e assim proporcionam uma estrutura favorável à queima. (CARVALHO; BRINCK, 2004).

Um resíduo muito significativo para a produção de briquetes advém das indústrias de carvão vegetal, onde a matéria-prima é perdida devido à fragmentação do produto gerando grande quantidade de resíduo na forma de finos de carvão. Anualmente são produzido cerca de 9 milhões de toneladas deste resíduo, sendo o Brasil o maior produtor. Devido aos impactos ambientais advindas da exploração de combustíveis fósseis, a escassez dos mesmos 


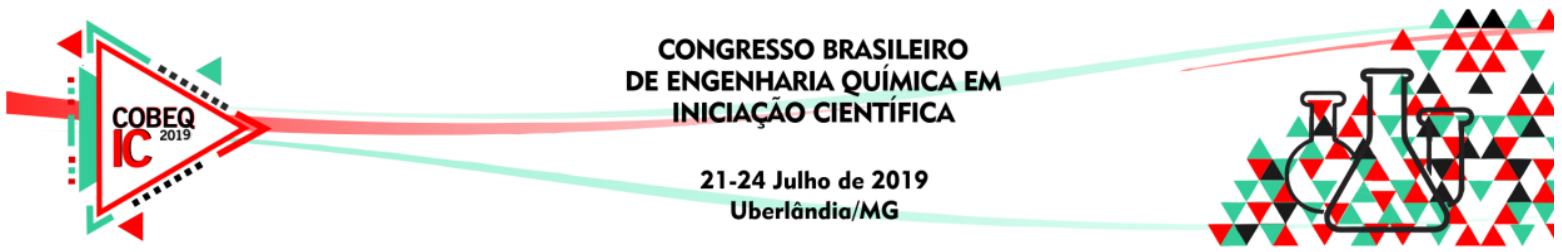

e a políticas brasileiras de incentivo a utilização de fontes renováveis, faz-se necessário pesquisas por fonte de energia (MORAES, 2011, MOTA; SILVA; GONÇALVES, 2009).

O biodiesel é uma fonte energética renovável que possui potencial para substituir total ou parcialmente o diesel. Porém a produção gera grandes quantidades de um coproduto denominado glicerina, que não pode ser descartada em corpos hídricos, pois dificulta a oxigenação de animais aquáticos. Além disso, seu preço no mercado brasileiro caiu consideravelmente desde o início da produção do biodiesel, o que fazer com que boa parte dos produtores de biodiesel prefiram armazenar a glicerina produzida, esperando que os preços voltem a subir (MOTA; SILVA; GONÇALVES, 2009).

Devido a grande oferta de glicerina no mercado, estudos têm sido feitos para encontrar soluções que melhor aproveitem este subproduto. Cordoba (2011) aborda a combustão de glicerina bruta. Já Astals et al. (2010) utilizou como um composto orgânico biodegradável aplicável no processo de digestão anaeróbica de esterco de porco. Anger et al. (2011) verificaram a conversão de glicerina num gás rico em hidrogênio de síntese. Sant'anna et al. (2011) estudaram a obtenção de briquetes a partir de resíduos agroindustriais como cascas de frutas, misturados com a glicerina bruta advinda do processo de biodiesel. Considerando o possível potencial energético da fabricação de briquetes produzidos a partir de resíduos industriais como a glicerina bruta e os finos de carvão vegetal, este estudo apresenta potencialidade na aplicação de resíduos como forma de geração de energia.

\section{MATERIAIS E MÉTODOS}

Os briquetes foram produzidos através destes resíduos industriais: finos de carvão vegetal (1); glicerina bruta (2) e amido de milho industrial não refinado (3). O resíduo 1 foi coletado em indústria de carvão localizada no município de Linhares/ES. O resíduo 2 foi preparado em laboratório com base nos dados da literatura. Já o resíduo 3, foi usado como aglutinante. Inicialmente realizou-se a análise granulométrica dos finos de carvão por meio da sequência de peneiras de modelo Granutest-ABNT de números 18, 20, 30, 40, 50, 60, 70, 80, 90 e 100, respectivamente e depois foram triturados no moinho de facas tipo Willey. Na etapa de mistura foram produzidos nove tipos diferentes de briquetes (Tabela 2), variando a composição entre os componentes, conforme definição realizada em pré-testes.

Tabela 1 - Componentes básicos da glicerina bruta.

\begin{tabular}{|c|c|c|}
\hline Componente & Unidade & Glicerina Comercial \\
\hline \hline Glicerina comercial bi-destilada & $\%$ massa & 80,0 \\
\hline Fosfato de sódio & $\%$ massa & 9,0 \\
\hline Óleo vegetal & $\%$ massa & 1,5 \\
\hline Água & $\%$ massa & 9,0 \\
\hline
\end{tabular}

Tabela 2 - Composição percentual dos briquetes produzidos.

\begin{tabular}{|c|c|c|c|c|c|c|c|c|c|}
\hline Componente & 1 & 2 & 3 & 4 & 5 & 6 & 7 & 8 & 9 \\
\hline \hline Amido & 5 & 5 & 5 & 10 & 10 & 10 & 15 & 15 & 15 \\
\hline Glicerina & 10 & 15 & 20 & 10 & 15 & 20 & 10 & 15 & 20 \\
\hline Carvão vegetal & 85 & 80 & 75 & 80 & 75 & 70 & 75 & 70 & 65 \\
\hline
\end{tabular}




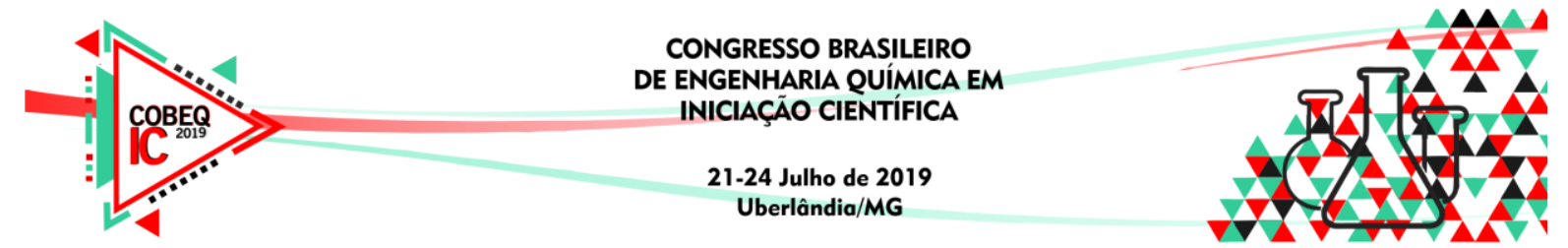

Após a mistura, a matéria-prima foi acondicionada em molde de aço cilíndrico e introduzidas na prensa hidráulica, de capacidade máxima de 15 toneladas. As cargas utilizadas no presente estudo foram 10 ton $\left(238 \mathrm{kgf.cm}{ }^{-2}\right)$ e 15 ton $\left(425 \mathrm{kgf.cm}{ }^{-2}\right)$. Para o primeiro foi utilizado o método proposto por Carvalho e Brinck (2004) para briquetes sem tratamento térmico, o objeto é abandonado de uma altura de $30 \mathrm{~cm}$ e colide com o solo e foram contadas as quedas suportadas até ocorrer a ruptura completa do briquete (PELISSARI; AMARAL; ESTEVES, 2012).

O teor de cinzas foi determinado conforme a ABNT NBR 8289-1983, em que um grama da amostra de briquete é triturado e seco. Em seguida, adicionou a amostra a um cadinho de massa conhecida e introduziu em um forno mufla à $700^{\circ} \mathrm{C}$, por aproximadamente 6 horas, sendo necessário resfriar em um dessecador e pesou a massa (PELISSARI; AMARAL; ESTEVES, 2012). A obtenção de teor de cinzas se deu conforme a Equação (1).

$T_{c}=\frac{M_{r}-M_{c}}{M_{a}} \times 100$

O poder calorífico foi determinado conforme estabelecido pela ABNT NBR8633/1984. Um grama da amostra, previamente triturada e seca, foi posta em combustão em uma bomba calorimétrica, sendo medido pela energia térmica produzida na combustão expresso em kcal. $\mathrm{kg}^{-1}$. Por fim, os valores de poder calorífico dos briquetes produzidos foram comparados com briquetes presentes na literatura.

\section{RESULTADOS E DISCUSSÃO}

Através da Tabela 3, observa-se um resultado satisfatório uma vez que 62,27\% das partículas de pó de carvão estão dentro da granulometria esperada uma vez que, o restante é considerado de tamanho inferior reduzindo a distância entre as partículas e atingindo o objetivo da etapa de trituração. Já na estimativa da capacidade dos briquetes produzidos de suportar o estresse provocado pelos impactos gerados durante seu manejo, foi empregado o teste de resistência ao impacto, dispostos na Figura 1 os resultados por meio de duas pressões de compactação utilizadas no estudo.

Tabela 3 - Granulometria da amostra dos finos de carvão.

\begin{tabular}{|c|c|c|}
\hline Mesh (\#) & Tamanho da partícula $(\mathrm{mm})$ & \% Retido \\
\hline \hline 18 & 1,00 & 0 \\
\hline$<20$ & $1,00-0,85$ & 4,54 \\
\hline $20-30$ & $0,85-0,60$ & 9,95 \\
\hline $30-40$ & $0,60-0,42$ & 19,37 \\
\hline $40-50$ & $0,42-0,30$ & 16,73 \\
\hline $50-60$ & $0,30-0,25$ & 20,50 \\
\hline $60-80$ & $0,25-0,18$ & 8,48 \\
\hline $80-100$ & $0,18-0,15$ & 8,75 \\
\hline
\end{tabular}




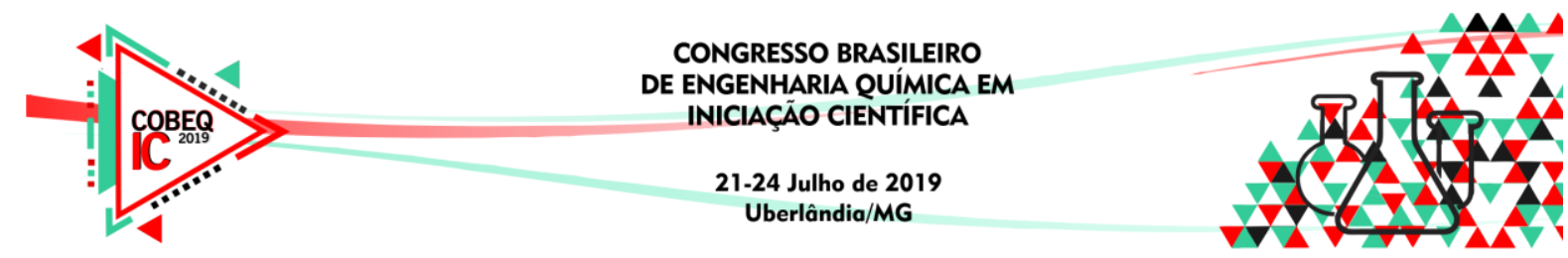

Figura 1 - Resistência ao impacto dos briquetes produzidos.

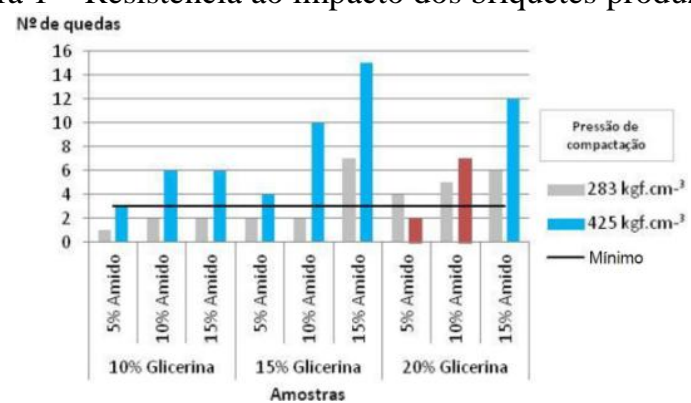

A Figura 1 confirma que as maiorias dos briquetes apresentaram resistência ao impacto satisfatória, comparando-se ao que foi definido por Carvalho e Brinck (2004) - que briquetes não curados devem suportar 3 quedas no mínimo para serem considerados resistentes, e para briquetes curados, no mínimo 10 quedas. Ao aumentar a concentração de aglutinante o briquete apresentou estrutura mais rígida e, assim uma maior resistência ao impacto, sendo esperado, pois o aglutinante age como ligante (MELO, 1999; MORAES, 2011).

Em relação à glicerina, ao alterar de $10 \%$ para 15\%, ocorre aumento geral na resistência de todos os briquetes nas duas pressões de compactação, mas em $20 \%$ na pressão de compactação $425 \mathrm{kgf.cm}{ }^{-2}$, houve uma queda média na resistência dos briquetes. Isso pode ser explicado, pois durante a compactação nessa pressão, os briquetes nas composições de 5 e 10 $\%$ de amido, apresentaram vazamento. Então, para essa pressão e fração de glicerina, os briquetes com 5 e $10 \%$ de amido não apresentam um resultado válido em número de quedas, pois a composição do briquete foi alterada pela perda de glicerina. Além do que, o próprio vazamento já mostra a impossibilidade da utilização dessas duas composições à pressão de $425 \mathrm{kgf.cm} \mathrm{cm}^{-2}$.

Ao diminuir a pressão de compactação de $425 \mathrm{kgf} . \mathrm{cm}^{-2}$ para $283 \mathrm{kgf.cm}{ }^{-2}$, houve uma redução no número de quedas suportadas em todos os briquetes. Entretanto, alguns briquetes suportaram 3 ou mais quedas, fato importante, levando em consideração que menores pressões demandam menos energia, reduzindo o custo de produção. Além disso, as composições que apresentaram vazamento na pressão de $425 \mathrm{kgf.cm}^{-2}$, não tiveram esse problema a partir da aplicação da pressão mais baixa, gerando briquetes com resistência satisfatória (PELISSARI; AMARAL; ESTEVES, 2012).

A fim de obter a quantidade de matéria que resta após a queima do briquete, foi feita a análise do teor de cinzas. Na Figura 2, são apresentados os valores percentuais médios de cada amostra de briquete em diferentes composições. As barras em vermelho representam as composições em que houve vazamento de mistura pela forma durante a etapa de prensagem.

Figura 2 - Resultados do teor de cinzas.

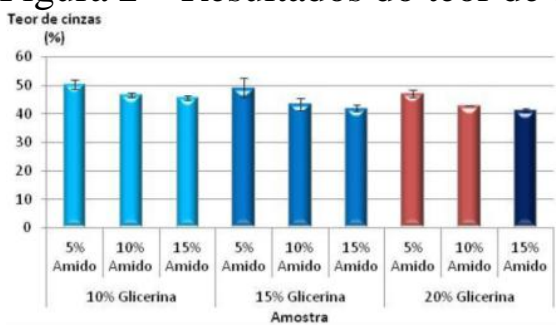




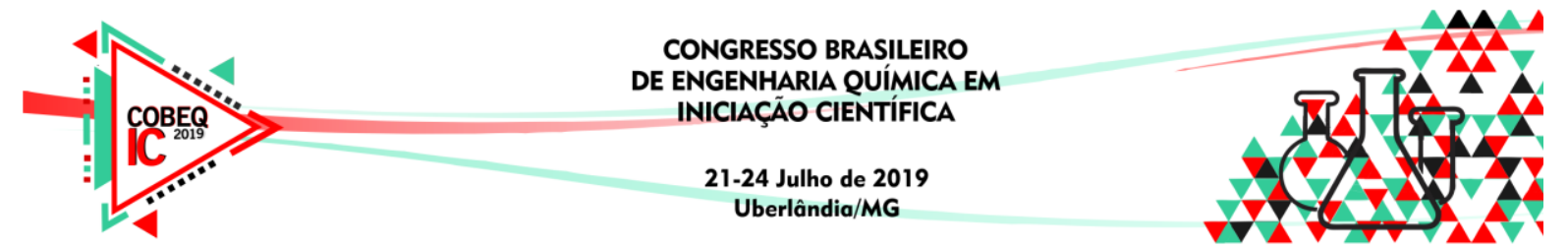

Todos os briquetes produzidos tiveram os valores de teor de cinzas na faixa de 40 a $50 \%$. À medida que se diminui a composição de carvão vegetal, a porcentagem de teor de cinzas também foi reduzida.

O melhor valor de teor de cinzas encontrado foi de $41,10 \%$, por apresentar menor percentual de materiais que não participaram da combustão, este foi obtido a partir da composição $15 \%$ de amido, $20 \%$ de glicerina e $65 \%$ de carvão. Em contrapartida, o pior valor obtido foi de 50,33 \% a partir da composição de $5 \%$ de amido de milho, $10 \%$ de glicerina e $85 \%$ de carvão. Observou-se que o teor de cinzas diminui à medida que a fração de carvão nos briquetes diminuiu. Obernberger e Thek (2004) afirmam que o elevado teor de cinzas (maiores que $37 \%$ ) pode ser uma indicação de contaminação da matéria-prima por materiais como areia, durante o armazenamento e manuseio. Porém as cinzas podem ser provenientes de substâncias inorgânicas e inertes, que constam grandes quantidades de contaminantes nas amostras ligados provavelmente ao manejo da carvoaria que são depositados no solo e aumentam as chances de acúmulo de detritos que passam despercebidos na etapa de remoção de materiais estranhos da matéria-prima por apresentarem granulometria baixa e coloração uniforme.

Com intuito de avaliar a energia liberada na queima dos briquetes, estes foram submetidos à análise de poder calorífico - energia liberada para cada unidade de massa, para cada composição percentual de glicerina, amido de milho e finos de carvão. A Figura 3 relaciona os valores encontrados com as composições de cada briquete. Os pontos em vermelho (amostras A5-G20 e A10-G20) representam as composições em que houve vazamento de mistura pela forma durante a etapa de prensagem.

Figura 3: Resultados do poder calorífico

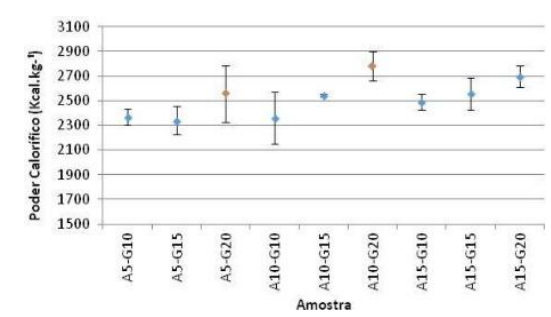

Como visto na Figura 3, há uma tendência de aumento do poder calorífico à medida que a fração de glicerina aumenta, confirmando sua influência positiva nos briquetes produzidos. Quanto ao poder calorífico, os valores encontrados nos briquetes variaram entre 2334 e 2781 kcal. $\mathrm{kg}^{-1}$, sendo os melhores resultados obtidos a partir dos briquetes que possuíam $20 \%$ de glicerina. Para essa fração de glicerina, os resultados foram: 2781, 2699 e $2558 \mathrm{kcal}_{\mathrm{kg}}{ }^{-1}$.

Um problema é a contaminação dos finos de carvão por detritos, provavelmente advindos do manejo não controlado do carvão, o que afetou negativamente os valores de teor de cinzas e poder calorífico, sendo importante uma separação mais elaborada que concentre mais os finos de carvão vegetal, ou então, de uma forma de manejo do carvão que evite submetê-lo a situações passíveis de contaminação.

\section{CONCLUSÃO}




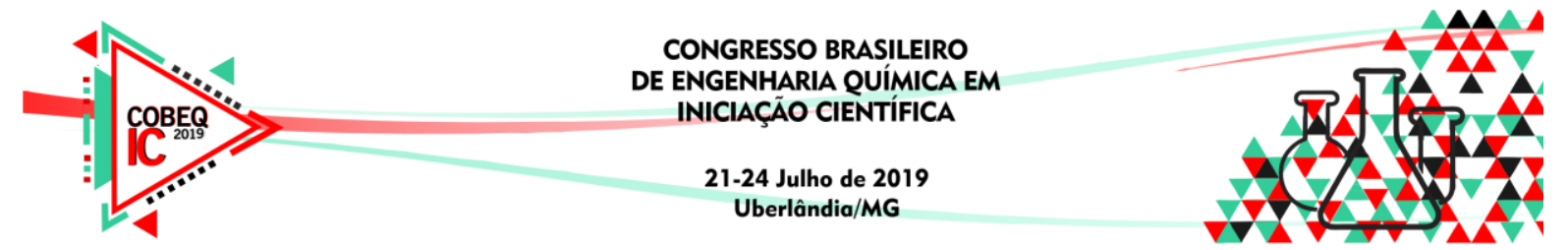

Foi observado que a confecção de briquetes por misturas de carvão vegetal, glicerina e amido de milho em diversas composições gera bons resultados, porém as variações de composição impactam diretamente nas características físico-químicas, mas a produção é uma técnica viável e proporciona um destino para os resíduos. Sugere-se que outras pesquisas possam verificar a produção de briquetes utilizando outros resíduos juntamente com os finos de carvão e a glicerina, verificando a utilização do amido e o uso de outros aglutinantes.

\section{REFERÊNCIAS}

Anger, S., Trimis, D., Stelzner, B., \& Makhynya, Y. (2011). Development of a porous burner unit for glycerine utilization from biodiesel production by Supercritical Water Reforming. International Journal of Hydrogen Energy, 36(13), 7877-7883.

Astals, S., Ariso, M., Galí, A., \& Mata-Alvarez, J. (2011). Co-digestion of pig manure and glycerine: experimental and modelling study. Journal of Environmental Management, 92(4), 1091-1096.

Carvalho, E. D., \& Brinck, V. (2004). Briquetagem em Tratamento de Minérios. Luz, A.B.; Sampaio, J.A.; Almeida, S. LM (Eds). Tratamento de Minérios. $4^{a}$ ed. Rio de Janeiro: CETEM/MCT, 613-635.

Cordoba, M., \& Yeferson, A. (2011). Estudo da combustão direta da glicerina bruta e loira como alternativa de aproveitamento energético sustentável (Doctoral dissertation, Universidade de São Paulo).

Melo, V. D. P. S. D. (1999). Produção de briquetes de carvão vegetal com alcatrão de madeira. Tese de doutorado - Universidade Federal de Viçosa, Viçosa.

Moraes, C. H. (2011). Processo e dispositivos para fabricação de briquetes a partir de finos de carvão vegetal com aglomerante a base de extrato de frutos de palmeiras da espécie syagrus. Patente com registro PI0903475-7A2. Brasil.

Mota, C. J., Silva, C. D., \& Gonçalves, V. L. (2009). Gliceroquímica: novos produtos e processos a partir da glicerina de produção de biodiesel. Química Nova, 32(3), 639-648.

Obernberger, I., \& Thek, G. (2004). Physical characterisation and chemical composition of densified biomass fuels with regard to their combustion behaviour. Biomass and bioenergy, 27(6), 653-669.

Pelissari, D. C.; Amaral, D. F.; Esteves, R. S. (2012). Avaliação da viabilidade técnica da incorporação do lodo primário da indústria de celulose na composição de briquetes. Monografia (Trabalho de conclusão do curso de Engenharia Química) - Faculdades Integradas de Aracruz, Aracruz.

Sant'Anna, M. C. S., Lopes, D. F. C., Carvalho, J. B. R., \& da Silva, G. F. (2012). Characterization of briquetes obtained agro-industrial residues. Revista Brasileira de Produtos Agroindustriais, 14(3), 289-294. 